the attack of typhoid, although one of them described himself as a "bilious" subject, nor is there anything in the course of the disease suggestive of cholelithiasis. "Some direct action of the specific micro-organisms on the liver or bile channels" (Da Costa) seems to me to be the most probable cause of the jaundice in these cases. Perhaps the description chosen by Mathieu ${ }^{31}$ - "benign hepatic typhoid"describes best the clinical aspect of these and similar cases.

It has often been remarked that every case of typhoid fever has to be looked upon as a "general infection with the typhoid bacillus." 32 Chantemesse ${ }^{33}$ seems to attribute all cases of jaundice, from the mildest to the acute yellow atrophy of the liver, to the presence of the typhoid bacillus in the portal system. But the precise seat and nature of the affection as well as the reasons why the infection occasionally attacks this particular organ at so early a stage, and why it all the same runs a mild course, while in others the implication of the liver quickly leads to a fatal termination, are questions which in the present state of our knowledge must remain unanswered. If I refrain from entering into speculations on these points, it is because I am mindful of the words which P. C. A. Louis has chosen as the motto and guide for his classical work on typhoid fever: "Je sais que la vérité est. dans les choses, et non dans mon esprit qui les juge, et que moins je mets du mien dans les jugements que j'en porte, plus je suis sûr d'approcher de la vérité."

REFERENCES.
Nouveau Diction. de Méd. et de Chir. Pratiques., T. xxxvi, p. 706. Paris : 884. Art. : Fievre Typhoid (Georges Homolle) and Diction. Encyclop. des ${ }^{884}$ Art. : Fievre Typhoid (Georges Homolle) and Diction. Encyclop des
sc. Med., iv, 15, p. $43^{2}$. Paris : r88. Article: Ictere (Bernheim). 2 Keller, If. Med. Complik, . $^{432 .}$ Paris : r88. Article : Ictere (Bernheim), Keller, i Rösli, W., Die Complikationen der Abdominaltyphus, Thesis. Zürich : ז880, p. ${ }^{6}$., 4 Liebermeister, C., Typlius Abdominalis in Ziemssen's Handb. der spec. Path. u. Ther., 3 Aufl, , 1886, Bd. ii, Th. i, p. 205.5 Wiedemann, F., Thesis. Thesis. München : $\mathbf{r o g}^{889}$. 'Ivanoff, M., Der Typhus Abdominalis in den Jahren r885-189o, Thesis. Zurich : r892, p. $3^{2}$. Werner, P., Ueb. Chlorotormbehdlg. des Darmtyphus, Petersourg. med. Woch., r892, p. ${ }^{25}$. r894, p. 42. 9 Rohfleisch, P. Ueber Verlauf des Typhus abdominalis bei r894, p. 42. der inner. Krankheiten. Leipzig: Vogel, 1893 , Bd. ii, p. 409. 11 Zülzer. W. Del Abdominaltyphus in Eulenburg's Realencyclopädie, 2 Aufl. 1885 , Bd. i, p. 5r. 12 Chomel, A. F., Lecons de Clinique Médicale faites a l'Hôte ineu de Paris, etc. Bruxelles: 1834, p. 260. 13 Louis, P. C. A., Recherches anat., pathol. et thérap. sur la maladie connue sous le nom de fievre typhoïde, etc., 2nd edition. Paris: 1841, p. 310. 14 Hoffmann, C. E., Untersuchungen $\ddot{i b}$. $d$. path.-anat. Veränderungen beim Abdominaltyphus, Leipzig, Vogel, 1869, p. 220. 15 Petrina, D., Ueber lethalen Ikterus im Verlauf von Typhus abdominalis, Prag. med. Woch. r88r, p. 403. 16 Hölscher, Aug., Die Complikationen bei 2,000 Fällen von lethalein Abdominaltyphus, Thesis, München, 189r, p. 5. 17 Horton-Smith, P., The Typhoid Bacillus and Typhoid Fever, Lancet, March 24 th, roo, p. 912. London, x884. 20 Curschman, H., Der Unterliebstyphus, Wien, 1898, p. ${ }^{6}{ }_{3}$. 21 Da Costa, T. M., On the Significance of Jaundice in Typhoid Fever, etc. A mer. Journ. of the Med. Sc., New Series, vol. cxvi, p. 12. 23 Hawkins, F., ()n Jaundice in Typhoid Fever, Proc. Med.-Chir. Soc., r897, p. 50, $5 \mathrm{r} .{ }^{23} \mathrm{Hoff}-$ mann, loc. cit., p. 220. ${ }^{24}$ Lemoine, George, Dict. Encyclop. des Sc. Med., Paris, 1885, iii, 18, p. 471, Art., Fièvre Typhoïde (George Lemoine). 25 Weil, A., Ueber eine eigenthümliche etc., Infektionskrankheit, Deut. Arch. f. kl. Med., x886, Bd. xxxix. ${ }^{26}$ Fielder, A., Zur Weil'schen Krankheit, Deut. Arch.f. $k l$. Med., 1888, Bd. xlii, p. $287 .{ }^{27}$ Weil'sche Krankeit in Eulenburg's Realencyclopädie, r8go, Bd. xxi, p. 26r-267, (A. Fränkel). ${ }^{28}$ Griesinger, W.' Ther., Bd ii, Abth. ii, 1857, p. 150, 2te Aufl. r864, p. 203. 29 Osler, W., Hepatic Complications of Typhoid Fever, Edin. Med. Journ. r897, p. 424. ${ }^{30}$ Naunyn, B., Klinik der Cholelithicsis. Leipzig. Vogel, 1892 p. 55. 31 Rev. de Méd., July, 1886. 32 Baumgarten, P. V., Jahresbericht, etc., 1895, p. 293. Anm. T. i., p. 763. Art.: Fievre Typhoïde (A. Chantemesse). 34
Paris, 189x.
Leick, Br. Deut. med. Woch. Leick, Br.. Deut. med. Woch., r897, Nos. 44, ${ }^{45}$, ${ }^{47}$. ${ }^{35}$ Ibid., 1898, No. 46.
Thesis, Paris, 189o, p. 210.

\section{INFLUENZA AND THE NERVOUS SYSTEM.}

By JAMES CARSLAW, M.A., M.B., C.M.

Dispensary Physician, Western Infirmary, Glasgow ; Recently Assistant to Professor of Medicine, Glasgow University.

THE discussion on "Influenza as itaffects the Nervous System," which took place at the meeting of the British Medical Association, and the detailed report of that discussion which appeared in the British Medical Journal on September 29th, have no doubt recalled to the minds of many physicians cases that have come within their own observation, and which at the time they may have only very hazily associated with the poison of influenza. It is to the cases of acute nervous disease-the first group of cases in Dr. Judson Bury's interest- ing paper-that this remark will most forcibly apply, the more chronic nervous sequelæ of influenza having been longer and more generally recognised. As during last winter and early spring several cases of acute illness, which might possibly bear this interpretation, occurred in the wards of Sir William Gairdner in the Western Infirmary, Glasgow, at his suggestion I have gone carefully over the records, and now publish the main facts regarding them in the hope that they may be of interest, especially in view of the probable repetition of influenza in an epidemic form within the next few weeks, as has happened so regularly during recent years. During the period referred to, during which influenza was being met with in private practice, though not to such an extent last year as in several previous years, there were 5 cases of acute meningitis in Sir William's male ward. One of these was in all likelihood a case of tuberculous meningitis, the patient having been previously in the same ward with what was considered to be tuberculous pyelitis, but I give details of the other 4 cases. No similar case of illness occurred in the female ward in the same period.

\section{CASE I.}

G. P., aged 26, a coachbuilder, was admitted to the Western.Infirmary in an unconscious and dying condition on December 26 th, 89

. History-His illness began on December oth with what appeared to be a feverish cold, but with severe headache. A doctor was called in on December 22nd, who regarded and treated the case as one of influenza. On the $23^{\mathrm{rd}}$ and 24 th severe headache continued, apparently without vomiting, and the temperature was as high as ro $4^{\circ}$. On the 25 th, about 2 P.M., he became unconscious with delirium and great restless

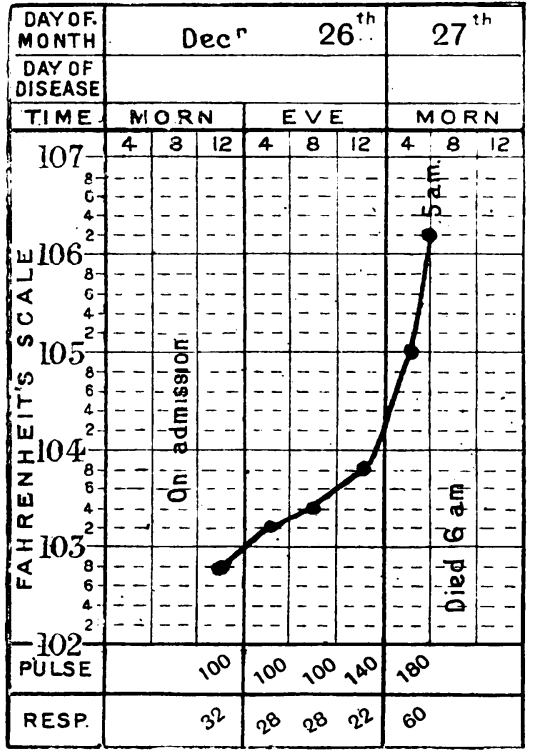

Condition on Admission. - He was quite unconscious and very restless tossing the bedclothes aside and pulling away the icecap that was applied to his head. There was inequality of the pupils, the right being dilated and insensitive to light. Occasional and transient conjugate deviation of the eyes to the left side was noticed. There was continual twitching of the fingers of the left hand with aimiess movements of that arm, while the right arm; otherwise there was no paralysis or convulsion.

Death arm ; otherwe rapidly worse, and the temperature, which was Death.-He became rapide steadily to ro6.2 ${ }^{\circ}$ at the time of death, which ro2.8 on seventeen hours after admission. The pulse increased witl the temperature, and the respirations before death numbered 60 per minute. The patient's illness lasted exactly seven days. Unfortunately no necropsy was permitted.

R. HI, aged 9, at school.
History.-This boy's previous health and family history were both good.

CAsE II. His illness may be described shortly as characterised by cere bral symptoms with febrile temperatures without any apparent cause and of remarkably sudden onset, he having been in good health till the evening of the day previous to admission. On January 13 th, r9oo, the patient was quite well till evening, when he complained of pains, first in his legs and later in his arms and head. On the morning of the r4th he complained of faceache and that he had a bad headache, chiefly occipital His mother administered a powder obtained from a chemist, containing hydrarg. cum creta and jalap. Soon after this his limbs were noticed to be rigid and his eyes staring, his neck, too, was arched back and stiff, 


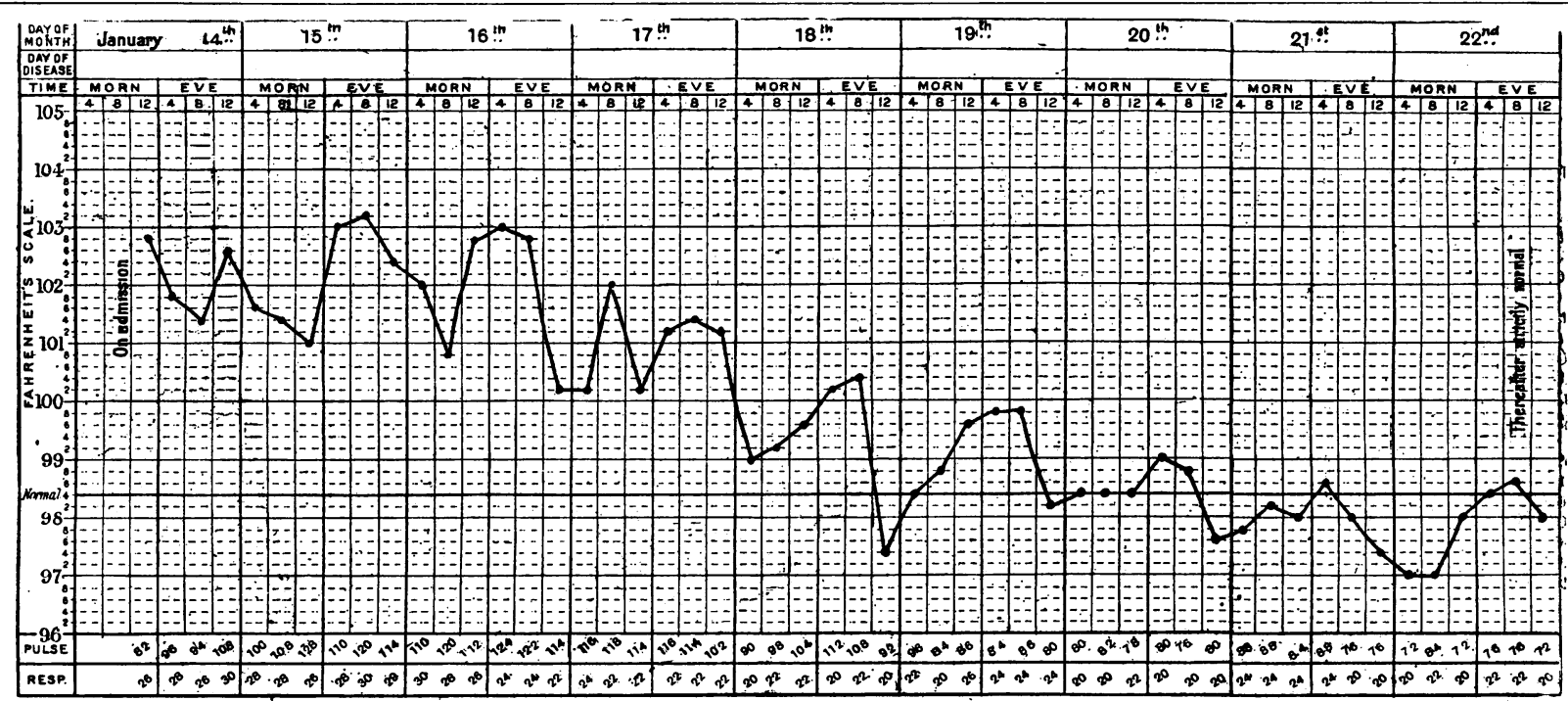

and when spoken to he did not answer. After a few minutes this condition was followed by twitchings approximating to general convulsions. At this time he also vomited everything that was given to him. He was seen by Dr. A. W. Russell, who sent him to the infirmary as soon as

Condition on Admission.-He was in a condition of extreme restlessness, his arms and legs being in continuous convulsions but not rhythmically. The restless movements of the limbs were quite irregular, and affected both sides equally; the body also was contorted, and the head twisted about in various directions. While unable to reply to questions he was not completely unconscious, and an hour after admission was able to indicate by nodding his head that he recognised his mother. The pupils were equal, moderately dilated, and sensitive to light. The temperature was ro2. $8^{\circ}$ and the pulse 82 per minute, and very good. The restlessness of
admission was greatly checked by the administration of $\frac{1}{2}$ gr. of morphine hypodermically, and this was repeated during the first night.

After-History.-Next day (January ${ }_{15}$ th) there was less insensibility, and no clonic convulsions, but some rigidity of the limbs; and it was noticed that the knee-jerks were not obtained. There was marked hyperxesthesia, especially about the head. The pulse was faster and weaker the respiration quiet and regular, and the temperature ranged from ror to ro3. $2^{\circ}$. The patient's bowels were very constipated, but nothing abnormal was detected on physical examination of the chest or abdomen, and the urine was free from albumen or sugar. On January i6th he was noted to continue very restless, fretful, and hypersensitive, but if anything, January 17 th, although there was no rigidity of the limbs or trunk, the head was noticed to be retracted, and attempts to flex the neck were resisted, and caused him to whimper as if in pain. However, he was on the whole more sensible, and suffered less pain, while he took nourishment readily. The temperature was still as high as ro ${ }^{\circ}$, but had fallen in the early morning to $100.2^{\circ}$ and the pulse was stronger again. From this date steady decline of the temperature took place, and after the roth it was practically normal. On the evening of the 17 th and thereafter a
pretty copious herpes labialis was present. On the roth he was reported to be fairly sensible and to be free from any complaint of pain in the head. He had apparently no defect of sight or hearing.

Convalescence.-Thereafter the boy made steady progress without recurrence of cerebral symptoms. He gained rapidly in liealth and strength, and was sent to the convalescent home at Lanark on February gth. On Jospital with the exception of some occipital headache, which his mother connected with his return to school. He was rather pale. He had had no vomiting, and his eyesight was found normal and the fundus oculi normal. His knee-jerks were still absent, but no ataxia was present.

CASE III

P. MCD., :aged 26, a coachman, was seen by me at his home at midday on January r8th, ro00, and as his condition was apparently serious and his surroundings unsatisfactory, he was transferred as soon as possible to the Western Infirmary, where he was admitted at 3 P.M.

Iistory.-Ten days previously he took a cold in his chest and had some cough and expectoration, but he did not consult a doctor, and was not compelled to leave his.work. On January r6th he had expressed himself as feeling much better, and he was at work as usual on January 17 th, driving in the city. He awoke from sleep on January roth about 4 or 5 A.M., complaining of great pain in the head and back. Some tea was vomiting was repeated four times during the next two hours. He gradually grew worse as the day went on, the headache being specially severe, and about noon he fell into an unconscious state, restless and struggling, talking wildly, and answering questions at random or not at all. The patient's previous health had always been good, and he was considered perfectly robust. He had not previously had any gastric symptoms, though inclined to constipation. His eycsight was perfect. and he had sionally during the previous six montlis lie had complained of a sharp pain through his head, of short duration, but sucl as to make him grasf perate in the use of alcohol, and lew moments. He was strictly ter. ease.

\begin{tabular}{|c|c|c|c|c|c|c|c|c|c|}
\hline $\begin{array}{l}\text { OAYOF } \\
\text { MONTH }\end{array}$ & \multicolumn{6}{|c|}{ Jany $18^{\text {th }}$} & \multicolumn{3}{|c|}{$19^{\text {th }}$} \\
\hline \multicolumn{10}{|l|}{$\begin{array}{l}\text { DAY OF } \\
\text { DISEASE }\end{array}$} \\
\hline TIME & \multicolumn{3}{|c|}{ MORN } & \multicolumn{3}{|c|}{ EVE } & \multicolumn{3}{|c|}{ MORN } \\
\hline Wo & 4 & 8 & 12 & 4 & 8 & 12 & 4 & 8 & $\frac{12}{12}$ \\
\hline $\begin{array}{ll}1110 & 8 \\
0 & 6 \\
0 & 4 \\
0 & 2\end{array}$ & $\overline{-}$ & $\begin{array}{l}-- \\
-- \\
--\end{array}$ & $\begin{array}{l}-- \\
-- \\
--\end{array}$ & $\begin{array}{l}-c \\
-\frac{2}{60} \\
-\frac{5}{E} \\
-\frac{5}{E}\end{array}$ & $\begin{array}{l}-= \\
\overline{-} \\
-\end{array}$ & 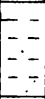 & $\begin{array}{l}-- \\
-- \\
-\overline{-} \\
-\bar{y}\end{array}$ & 产 & $\begin{array}{l}-- \\
-\overline{-} \\
--\end{array}$ \\
\hline $\begin{array}{ll}5 & 8 \\
\text { I } & 4 \\
& 2\end{array}$ & $\begin{array}{l}\overline{-} \\
-\overline{-} \\
-\overline{-}\end{array}$ & $\begin{array}{l}-- \\
-- \\
--\end{array}$ & $\begin{array}{l}-- \\
-- \\
-- \\
--\end{array}$ & $\begin{array}{r}-5 \\
-5 \\
-5 \\
0 \\
---\end{array}$ & $\overline{-}$ & $\overline{-}$ & $\begin{array}{l}-- \\
-- \\
--- \\
--\end{array}$ & $\begin{array}{l}\frac{9}{2} \\
\frac{9}{9} \\
\frac{9}{0}\end{array}$ & $\begin{array}{l}-- \\
-- \\
--\end{array}$ \\
\hline & $\overline{-}$ & $=-$ & $=-$ & $\overline{-}$ & - & & -- & & $=-$ \\
\hline$\frac{\pi}{4}{ }^{2}$ & $\overline{-}$ & -- & $=$ & $=-$ & - & & - & & \\
\hline "LULSE & & & & & & & & & \\
\hline RESP. & & & & & & & & & \\
\hline
\end{tabular}

Condition on Admission.-He was in an unconscious condition,' but restless and struggling in such a way that a male attendant had to be got to keep him in bed. He was continually moving his arms and his legs in an aimless way, and all attempts to alter his position were strongly resisted. There was, however, no real convulsive movement, and no paresis of one: or other side of the body was noticed. Examination of the eyes showed. slight ptosis on the left side, and also inequality of the pupils-the left being dilated and insensitive to light, the right small and responding rather sluggishly. In the evening there was noticed, in addition to left ptosis, some external strabismus of the right eye. Moreover, the left, pupil was more widely dilated, and the right contracted and scarcely, if at all, responding to light. Some retraction of the head was also. abserved, but not of the abdomen. Tache cérébrale was easily elicited. The condition of restlessness continued, but it was noticed that in struggling more power was exercised by the right arm than by the left, so as to suggest some paresis of the left arm. Twitching of the hand and fingers were noticed as occurring especially on the right side. The: heart and lungs appeared, on physical examination, to be normal. The: bowels were not moved in spite of croton oil administered. The urine was drawn off by catheter and found free from albumen, blood, or sugar. His temperature ranged from ror. $2^{\circ}$ to $102.2^{\circ}$; his pulse from 90 to roo,
and was regular: his respirations from 30 to 40 , and were rather irregular, but never of the Cheyne-Stokes type.

Death.-The patient continued in the same restless state during tho night, becoming gradually weaker, however, and died on January 1 gth, at ro A.M., his acute illness having lasted only thirty hours.

Necropsy.-Permission to examine the head was granted, but not the body. The report of Dr. A. $R$. Ferguson, who made the examination states that there was a general purulent leptomeningitis, well marked both over the convexity and at the base of the brain. The purulent exudation, examined microscopically, was found to contain a few diplo cocel. The pus cells were vacuolated and broken down in appearance. Cultures were tried from the exudation, but failed to produce any growt 1 . The lateral ventricles were not dilated; the slight amount of fuid in the base of the brain there was a striking alteration in the pituitary 
body, the situation of which was occupied by a comparatively bulky tumour of exceedingly soft consistence and pronounced hæmorrhagic
character. This was found microscopically to have the structure of a character. This was found microscop
round-celled sarcoma of alveolar type.

\section{CASE IV.}

J. K., aged 17, was admitted to the Western Infirmary at 5.45 P.M. on March 3 rst, 1900, in an unconscious condition.

History.-He appears to have been strong and healthy, but on March 28th he began to suffer from a fererish cold and severe headache, although he was at his work till the 3 oth. That evening his headache was and an ho He dida not ind conscious, and was soen cond of extand of right larer than the left but on stimulation bylight both to an equal size There was no ptosis nor strabismus, and no facial paralysis. Muscular power did not seem to be impaired either in the arms or legs, and when any attempt was made to change his position he resisted powerfully with all his muscles. He was a muscular and healthy looking youth, and nothing abnormal was discovered in his chest or looking youth, and nothing abnormal was discovered in his chest or abdomen. His face was flushed. His temperature, which was ro5 on tions were regular.

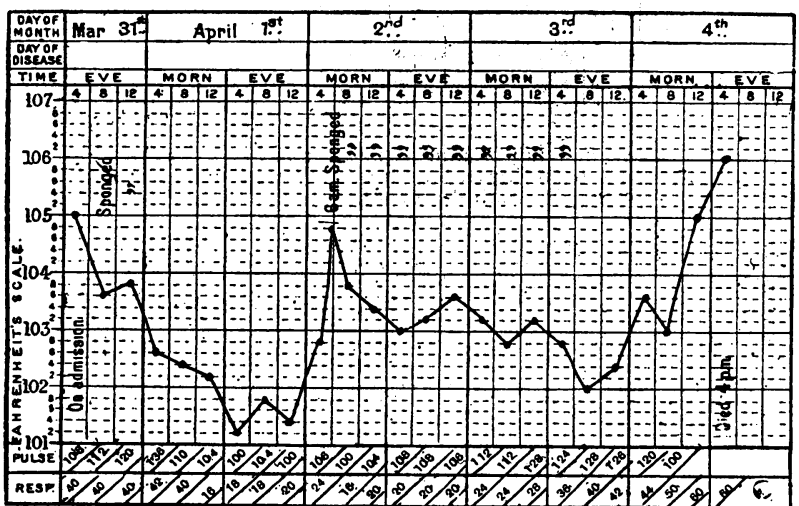

After-History.-Next day (April ist) there was not much improvement, though after free action of the bowels his mind seemed clearer, and he could talk and answer questions. There was retention of urine, and what was drawn off by catheter contained some albumen. The pupils were gtill noticed to be unequal, but no other evidence of paralysis was detected. The tongue was very dry and coated, though the temperature was res low gone up again during the night to $104.8^{\circ}$, and this was associated with acute delrium, so that a male attendant was required to keep him in bed. However, he quieted down during the day, and the temperature of the head were noticed. In the evening he could respond to questions, but rather at random.

Death.-The next day his condition was unsatisfactory. He was losing strength steadily, and was in a constant state of muttering delirium, strength steadily, and was in a constant state of mutering delirium, which condition passed into coma on April 4 th, the patient dying on the ally for only six days. Unfortunately his friends did not allow a postmortem oxa six days.

These four patients were all the subjects of acute meningitis, but it is possible that the meningitis may have been the principal incident of an attack of influenza, or, on the other hand, the infection may have been a mixed one, and the influenza may simply have paved the way for the entrance of other toxic agents as well as Pfeiffer's influenza bacillus. Unfortunately, although three of the cases were fatal, post-mortem examination was only permitted in one of them, and in that case the examination was limited by the friends to the head. This case (Case III) I shall consider first, and from the pathological report it will be seen that the meningitis was found to have been of a very acute type. Its bacteriology, however, was not very satisfactorily made out. No doubt diplococci, and those of comparatively large size, were found in the films prepared at the post-mortem examination, but the attempt to make cultures from the purulent effusion failed, no growth being got after ample incubation of the tubes. It is possible that the influenza bacillus was present in addition to diplococci, both being difficult to cultivate except in specially prepared media ; but it may be that a diplococcic infection alone was passed on from the respiratory passages, the catarrhal affection of which, whether influenzal or not, would favour such. If so, could the fact of a tumour being present in the base of the brain have had any influence in determining the inflammation of the meninges? This particular case was of special interest, apart from the acute and fatal meningitis, from the discovery of a sarcoma of the pituitary body. The patient was previously known to me, and had always been considered a healthy, strong, and well-developed young man, and had presented none of the symptoms of acromegaly. The only symptom that could be considered to bear any relation to this tumour was mentioned by his friends only after his death-namely, that during the previous six months he had occasional attacks of pain through his head; which were of short duration, and caused him to hold his head with both his hands for a few minutes. Probably the tumour had not reached the stage in its development which would have produced characteristic symptoms. The other striking features of this case were the sudden onset and the rapid progress of the acute symptoms, death occurring within thirty hours; also the extreme and aimless restlessness of the patient in his consciousness, so that it was difficult to keep him in bed, and the presence of distinct pressure symptoms indicating that the base of the brain was involved in the inflammation as well as the convexity.

The other fatal cases (Case I and Case IV) resembled one another very closely, though the former was under observation in the infirmary for too short a time to permit one to dogmatise about it. In both the illness altogether lasted about a week, and both patients were strong and healthy young men, probably not the subjects of tuberculous disease. In both the first symptoms were those of influenza, headache being early and severe, and they passed somewhat suddenly into a state of unconsciousness from which they never rallied.

The case of the young boy (Case II), occurring as it did in the ward at the same time as Case III, was very interesting, and its exact nature was a question of some difficulty. The patient was probably suffering from acute inflammation of the cerebral, and possibly also of the spinal, meninges. Its onset was sudden, and the meningeal symptoms were early and severe, and, with other characteristic symptoms, he had a very typical herpes labialis. Was the case, then, one of epidemic cerebro-spinal fever? No confirmation of such a diagnosis could be got from his history, and his parents and a family of younger children at home were in good health. May it have been a sporadic case, or may we place it along side of such cases as were cited by Dr. Judson Bury as probably due to the bacillus of influenza? The possibility of this and the earlier cases having had some such relation to influenza was considered by Sir William Gairdner at the time in his clinical lectures to the students.

The points I would specially draw attention to in all these cases may be shortly stated. The illnesses occurred in otherwise healthy subjects, and at a time when influenza was present in the neighbourhood. Some of the cases had early catarrhal symptoms, considered by their medical advisers to be of the nature of influenza. In all severe headache was prominent, and grave cerebral symptoms developed with alarming rapidity, and with no apparent cause, in the ears or elsewhere. They were all characterised by very restless delirium, with in the main little or no paresis of limb or ocular muscle to indicate any important localisation. Most likely the meningitis was more vertical than basal, though in the only case that was examined post mortem the purulent exudation was found very prominently both at the base and on the convexity, and in this case there had been prominent clinical facts in regard to the pupils, ptosis, and strabismus, indicating that the base of the brain was involved.

While there was no case of similar acute disease in the female ward during last winter or spring, perhaps it may be of interest to record the summary of a very marked case of postinfluenzal multiple neuritis, which was in Sir William Gairdner's female ward in the spring of 1899 .

M.D., aged 40, a dressmaker, was admitted to the Western Infirmary ou my recommendation, on April 7 th, 1899 , suffering from advanced peripheral neuritis, most marked in the lower limbs, involving also the bain, with some sper limbs. In addition to paralysis there was much pain, with some slight disturbance of sensation. There was great wasting to characteristic contractures. The superficial and deep reflexes were gone, and the reaction of degeneration was present. The eves and speech were normal, and there was nothing amiss with the bladder or the rectum; there was no fever.

The onset of the patient's illness had been eight weeks before admission, when she had symptoms of influenza-catarrh, cough, and general weakness. She, however, persevered at her work against medical advice, 
and four weeks before admission paresis of the lower limbs began, with numbness and tingling. These symptoms increased gradually, later affecting the upper limbs also, though to a less extent. An attack of gastric disturbance with jaundice shortly preceded admission.

The previous health and family history were satisfactory. There was no history of alcoholism or of any other possible cause for her symptoms except the influenza.

Under treatment by massage there was rapid diminution of the œdema and gradual improvement in regard to the pain, and gradual return of muscle power. The massage was kept up for ten weeks, by which time the patient was able to walk about the ward, and she went home almost

This patient's illness corresponded with the usual features of alcoholic peripheral neuritis, and there was at first a suspicion that it might be of that nature. However, her own assurances on this point were amply corroborated by the members of her own family, by her employer, and by her physician. Moreover, although she had had a distinct attack of influenza, she did not lay up for any time, and against medical advice persevered at her work, so that there was all the more likelihood of such a complication as neuritis taking place. Cases might be multiplied either from the wards of the infirmary or from private case books of other forms of nervous disease of a chronic nature-the second group in Dr. Bury's paper-which are now recognised to be not very infrequent sequelæ of influenza, but I content myself with narrating the above as a recent and very typical case.

I am indebted to Sir William Gairdner for the suggestion to record these cases, and for his kind help in the preparation of this paper. The original reports of the cases were all the work of Dr. A. L. Watson, recently Resident Physician for Sir William in the Western Infirmary, and it is due to him to acknowledge here the careful and thorough way in which they were recorded.

\section{THE DETECTION OF ARSENIC IN BEER AND BREWING MATERIAL.}

BY SHERIDAN DELÉPINE, M.B., Procter Professor of Pathology, Owens College, Manchester.

Tнe preliminary note contributed by Dr. Tattersall and myself $^{1}$ had for its object to prevent the further use in brewing of some sugars which we had found to be the sole cause of the dangerous contamination of beers brewed in Salford. Dr. Tattersall's preliminary report to his Committee dealt only with this practical aspect of the question, a more detailed account of the work done being reserved for a more complete report. The announcements and suggestions which continue to be made have convinced us of the desirability of publishing a short account of the methods of analysis which has been selected, and of the considerations which have led me to adopt certain standards for the purpose of interpreting the results obtained.

The Wide Distribution of Arsenic in Nature.

In the first place, I had to keep in mind the extraordinary ubiquity of arsenic. It is a fact of common knowledge among chemists ${ }^{2}$ and biologists ${ }^{3}$ that arsenic is one of the most widely-distributed substances. It is frequently associated with other metals and sulphur, in various mineral products. Many soils contain arsenic ; vegetables growing in such soils may contain traces of that body, which is more abundant in their seeds. The soil may also be rendered arsenical artificially, as when various chemical products are thrown upon the ground. Contamination of water may occur under those circumstances. Some valuable mineral waters, more especially the ferruginous waters, contain minute quantities of the poison, owing to their passage through arseniferous strata. It has also been found in sea water. It has even been lately asserted that arsenic is a normal constituent of the human body. Taking these things into consideration, I thought that the mere detection of traces of arsenic would not be sufficient to prove that any sample of beer was actually dangerous to health. No authoritative statement could be found showing that pure beer should be absolutely free from arsenic ; on the other hand, it was quite conceivable, on the ground of general knowledge, that minute traces of arsenic might occur in beer even prepared from the best material, and that this must have, in fact, occurred at all times since beer began to be brewed from malt and hops.
What is a Dangerous Amount of Arsenic in Beer? The first thing to do was therefore to determine what amount of arsenic might reasonably be considered dangerous for a man taking a considerable amount of beer, and, if that proportion was reached, it was obvious, first, that no argument based on the general prevalence of arsenic could shake the conviction that the presence of that body in the incriminated beer was harmful; and, secondly, that the presence of a harmful amount of arsenic in beer could not be accounted for by the use of natural products which had been employed in the manufacture of beer for generations without giving rise to any striking outbreak of disease, but that come substances capable of becoming loaded with arsenic had lately been used by a certain number of brewers, either in the treatment of ordinary brewing material or as substitutes for some important article. I have, therefore, attempted to fix a standard of the minimum dose that might reasonably be considered harmful, on the supposition that half a gallon of beer was consumed daily.

About $0.04 \mathrm{gr}$. of arsenious acid is about the minimum dose administered daily for medicinal purposes (this dose corresponds to about 2 minims of Fowler's solution twice a day). Such a dose may be taken for a considerable time by most people without any bad effects, but taking idiosyncrasy into account nobody should take such a quantity of arsenious acid daily and more or less indefinitely without knowing it or without medical advice. I therefore felt justified in conconsidering that any beer containing about $0.08 \mathrm{gr}$. of arsenious acid per gallon (that is, I part of $\mathrm{As}_{2} \mathrm{O}_{3}$ per 875,000 parts of beer) should be condemned. This could be done without, in the short time at my disposal, attempting to determine whether traces of arsenic were permissible in beer or not.

\section{Reinsch's Process.}

The selection of a proper method for the detection of arsenic in beer was not less important. The two most reliable qualitative methods are undoubtedly the Marsh's and the Reinsch's, but neither of these had been extensively used for the purpose of estimating the amount of arsenic in beer and some of the organic substances we had to deal with. At any rate, references to such examinations were not easy to find." Several comparative trials showed me that the Reinsch's test was eminently applicable to the detection of arsenic in beer, glucose, hops, and all the other organic and inorganic compounds I had to deal with. With regard to the Marsh's test, it was inapplicable to beer which had not been previously treated so as to break up the organic matter. I therefore thought that if the first method could be made to reveal sufficiently small quantities of arsenic in beer, and be used to estimate approximately the quantity of the poison in a moderate amount of fluid, it would be preferable

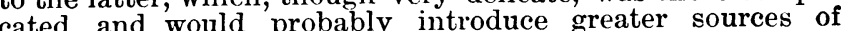
experimental error. By conducting the Reinsch's test with care, I found that it was easy to detect the presence of arsenic in 100 c.cm., and even as little as $20 \mathrm{cccm}$., of some of the suspected beers. On the other hand, no distinct trace of arsenic could be found in as much as $200 \mathrm{c.cm}$. of beer brewed in Bavaria, where the use of malt substitutes is prohibited by law.

The next thing to ascertain was the amount of arsenic that must be present in beer in order that the test should give unmistakable results. From a number of samples of beer, which had carefully been tested for the presence of arsenic, one was selected in which no trace of the poison could be found. With this beer standard solutions, containing respectively $0.002,0.001,0.0008$, $0.0006,0.0004,0.0002,0.0001,0.00005$ gram of arsenious acid per . Then $100 \mathrm{c.cm}$. of each one of $100 \mathrm{c.cm}$. of beer were made. Then solutions were tested by Reinsch's method, and it was found that a sublimate composed of small but clear crystals of arsenious acid could be obtained from the solution containing 0.0001 gram of arsenious acid per cent. (I part per million) without any previous concentration of the beer. The amount of sublimate obtained was just enough to obtain confirmation of its nature by the production of the yellow arsenite of silver. It will be noticed that the test demonstrates easily a quantity of arsenic smaller than that which I have given above as objectionable, and 